要 旨 ビニルトリアジン誘導体として, 2-アミノ-4-o-トルイジノ-6-ビニル-s-トリアジン (ATV T）を合成し，アゾビスイソブチロニトリル（AIBN）を開始剤とし，60C でジオキサン溶液重合を行 なった結果, 重合速度式として, $R_{p}=2.37 \times 10^{-3}[\mathrm{AIBN}]^{0.5}[\mathrm{ATVT}]^{1.0}$ を得た。また, スチレン, フ クリル酸メチル, アクリロニトリル, 酢酸ビニルと共重合を行ない, スチレン $\left[\mathrm{M}_{1}\right]$ の場合, $r_{1}=0.45$, $r_{2}=0.93$, これから ATVT の $Q=1.05, e=+0.13$, MA の㙏合, $r_{1}=0.33, r_{2}=1.22$, これから ATVT の $Q=0.72, e=-0.36$ を得た。

\section{1. 緒言}

従来,ビニルトリアシンンについては,C.G. Overberger ら $^{1), 21}$ の 2, 4-ジアミノー6-ビニル-sートリアシシンおよび 2-アミノ-4-アニリノー6ービニル-sートリアシンン合成と 重合の簡単な報告と, A.T. Coscia $5^{31}$ の 2, 4-ジィチ ルー6ービニル-Sートリアジンの報告がある。

そこで反応性高分子として期待できるポリビニルアミ ノトリアジンの合成を目的とし，まず，ビニルトリアシ ン誘導体として 2-アミノー4-0-トルイジノ-6-ビニル-sトリアジン（ATVT と略す）を合成し，その単独重合 および共重合を行なったので報告する。<smiles>C=Cc1nc(N)nc(Nc2ccccc2C)n1</smiles>

\section{2. 実験}

2.12 2-アミノ-4-o-トルイジノ-6-置換-sートリアジン ○ートルイジノ基をもつトリアシンはあまり知られてい ない4)ので，モノマーと比較するため，二三のトリアシ ンを合成した。C.G. Overberger ら ${ }^{51}$ の方法を参考にし て, ○ートリルビグアニド (大内新興化学工業製) と 5 倍 量のカルボン酸メチルェステルを炭酸カリを触媒とし てメタノール中で反応させ, 求めるトリアジンを得た (Table 1 参照)。

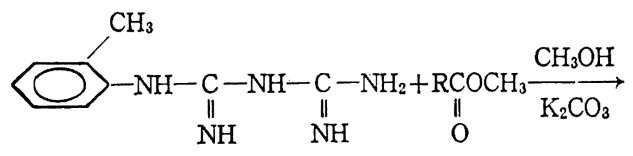

* 東京工業大学工学部高分子工学科（東京都目黒区大 岡山 2-12-1)<smiles>[R]c1nc(N)nc(Nc2ccccc2C)n1</smiles>

\section{2 モノマー合成}

C.G. Overberger ら"の方法を参考にして, 次の反応 式で示されるよらに ○ートリルビグアニドとアクリル酸 クロリドを水酸化カリウムを脱塩酸㨈としてアセトン中 で反応させATVTを得た。収率 $27 \%$ ，融点 $168 \sim 169^{\circ}$.

C、含水エタノールから再結晶。

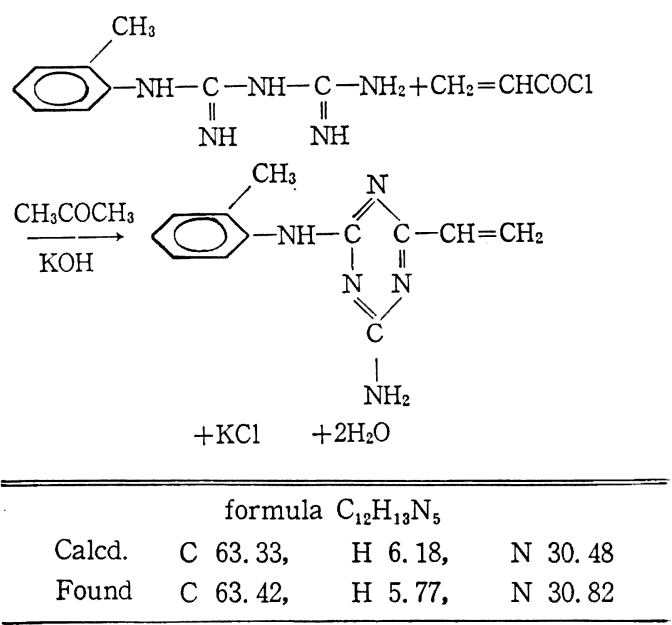

\section{3 重 合}

ATVT は融点 $168 \sim 169^{\circ} \mathrm{C}$ の固体のため, 重合は単 独重台, 共重台ともアンプルを用いた溶液重合を行なっ た。すなわち, ATVT およびアゾビスイソブチロ ト リル（AIBN）のシオキサン溶液を常法で洗浄したアン プルに仕込み, 凍結, 脱気をくりかえした後, 真空下で 溶封し, 所定温度の恒温槽中で所定時間静置重合を行な 
った。反応後、ポリマーをメタノールに沈殿させ、口 過, 洗浄, 乾燥し重量法により重合速度を求めた。

\section{4 共重合体の組成決定}

アクリル酸メチル（MA）との共重合体は元素分析に よりその組成を求めた。スチレン (St)，アクリロニト リル (AN), 酢酸ビ ニル ( $\mathrm{VAc})$ との共重合体は, $\mathrm{K}$. Knappe ら $ら^{61}$ の方法を応用し, ポリマーを酢酸に溶解し, クリスタルパイオレットを指示薬とし, 過塩素酸一水酢 酸溶液によりトリアシン環を定量し, その組成を求め た。

\section{3. 結果および考察}

3.12 -アミノ-4-0-トルイジノ-6-置換-s-トリアジン 酢酸メチル, プロピオン酸メチル, $n$ 一酪酸メチル, iso 一酪酸メチル，あるいはフェニル酶酸メチルとロートリル ビグアニドとの反応の結果を Table 1 に示した。比較 のためATVTの結果を付記した。

Fig. 1 に島津 SV-50 型分光光度計により測定した No. 4, 5, 6 (Table 1) のUV スペクトルを示す。No. $1 \sim 5$ はほとんど同一の吸収を示し, $\lambda_{\max }$ と $\lambda_{\min }$ の 吸光係数 $(\varepsilon)$ の差がわずかである。これは ○ートルイシ ノ基だけでなく，2，3-ジメチルアニリノ基や $\mathrm{N}$-エチル 一-トールイジノ基などを持つトリアジンについても認め られていて ${ }^{4 a)}$ ，この shoulder type になる原因は ○ーメ チル基などによる立体障害のためとされている。ATVT ではほとんど吸収が認められない。

\section{2 単独重合}

ジオキサン溶液重合は均一系で進行し, 得られたポリ

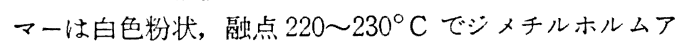
ミト， シメチルスルホキシド (DMSO), 水酶酸などに 可溶である。 $\mathrm{KBr}$ 法, 日立 EPI-S 2 型赤外分光光度計 で測定したATVT，ポリ-ATVT および 2-アミノ-4

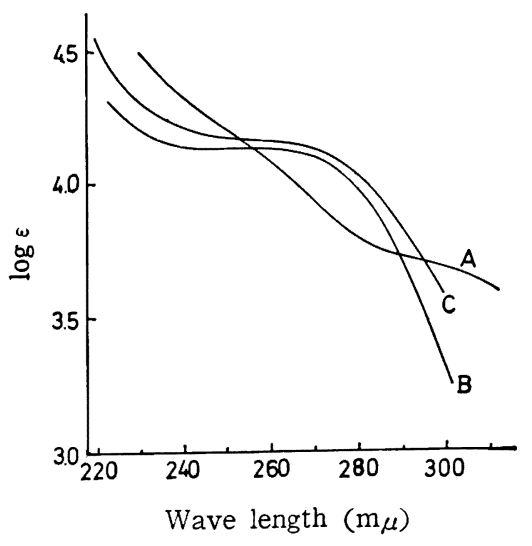

Substituent,

A: vinyl (ATVT), B : isopropyl, C: benzyl

Fig. 1. The ultraviolet spectra of 2-amino-4-otoluidino-6-substituted-s-triazine in ethanol.

-o-トルイジノ-6-イソプロピル-s-トリアジン (Table 1. No. 4) のIR スペクトルを Fig. 2 に示す。各試料 ともに 3000〜3500, 1500〜1600, $820 \mathrm{~cm}^{-1}$ にアミト リアシンンの特性吸収》がみられる。ポリマーにはATVT にみられる $960 \mathrm{~cm}^{-1}$ のビニル基の吸収が消減している。 また, $725 \mathrm{~cm}^{-1}$ と $750 \mathrm{~cm}^{-1}$ のフェニル基によると思わ れる吸収はポリマーとイソプロピルトリアジンはよくー 致し, ATVT とはいくぶん異なっている。したがって, 先のUVスペクトルの結果とあわせて，ビニル基とトリ アジン環との共鳴により, ○ートリル基の状態が変化して いるものと思われる。以上の結果より重合は一般のビニ ル重台により進行していることがわかる。

次に, ATVT 濃度, AIBN 濃度, 重合温度などを変 光た場合の反応率一重合時間の関係を Fig. 3 亿示す。

Table 1. Synthesis of 2-amino-4-o-toluidion-6-substituted-s-triazine.

\begin{tabular}{|c|c|c|c|c|c|c|c|}
\hline \multirow{3}{*}{ No. } & \multirow{3}{*}{$\begin{array}{c}\text { Substituent } \\
\text { R }\end{array}$} & \multirow{3}{*}{$\begin{array}{c}\text { Yield }^{a} \\
(\%)\end{array}$} & \multirow{3}{*}{$\begin{array}{l}\mathrm{mp} \mathrm{p}^{\mathrm{b})} \\
\left({ }^{\circ} \mathrm{C}\right)\end{array}$} & \multicolumn{4}{|c|}{ Ultraviolet absorption spectrac) } \\
\hline & & & & \multicolumn{2}{|c|}{$\lambda_{\max }$} & \multicolumn{2}{|c|}{$\lambda_{\mathrm{m} \ln }$} \\
\hline & & & & $\mathrm{m} \mu$ & $\varepsilon \times 10^{-4}$ & $\mathrm{~m} \mu$ & $\varepsilon \times 10^{-4}$ \\
\hline 1 & $\mathrm{CH}_{3}$ & 41 & $201.5 \sim 202.0$ & 260 & 1.33 & 253 & 1.32 \\
\hline 2 & $\mathrm{C}_{2} \mathrm{H}_{5}$ & 42 & $195.5 \sim 196.0$ & 261 & 1.41 & 252 & 1.38 \\
\hline 3 & $n-\mathrm{C}_{3} \mathrm{H}_{7}$ & 37 & $153 \sim 154$ & 261 & 1.35 & 251 & 1.33 \\
\hline 4 & iso- $\mathrm{C}_{3} \mathrm{H}_{2}$ & 33.5 & $161.5 \sim 162.0$ & 262 & 1.37 & 249 & 1.32 \\
\hline 5 & $\mathrm{C}_{6} \mathrm{H}_{5} \mathrm{CH}_{2}$ & low & $154 \sim 155$ & \multicolumn{4}{|c|}{ non-specific absorption } \\
\hline 6 & \multicolumn{2}{|c|}{$\mathrm{CH}_{2}=\mathrm{CH}(\mathrm{ATVT})$} & $168 \sim 169$ & \multicolumn{4}{|c|}{ non-specific absorption } \\
\hline
\end{tabular}

a) reaction condition; Temp. $55^{\circ} \mathrm{C}$, Time $110 \mathrm{hr}, \mathrm{K}_{2} \mathrm{CO}_{3}$ catalyst in methanol

b) recrystallized from ethanol-water mixture

c) measured in ethanol, and No. 1 4 gave the same spectra for shoulder type 
Wave length $(\mu)$

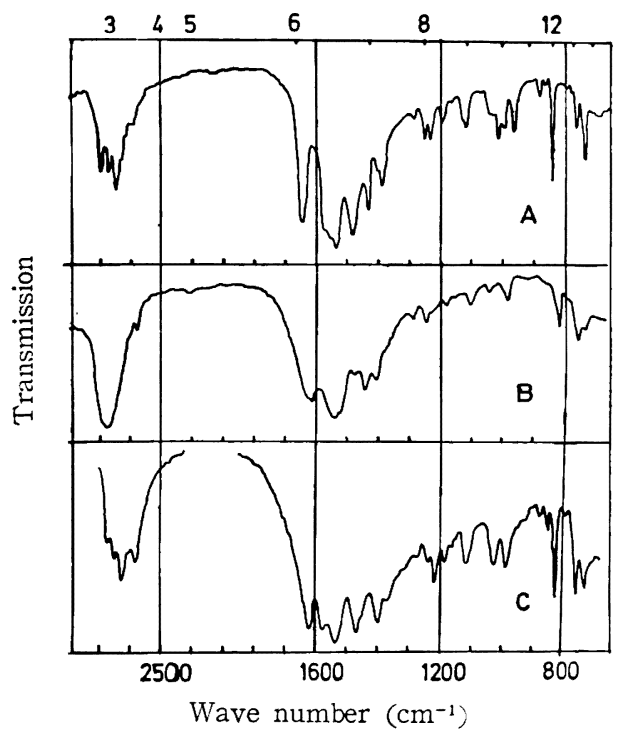

A: monomer (ATVT) B: poly-ATVT

C: 2-amino-4-isopropyl-6-o-toluidino-s-triazine

Fig. 2. Infrared spectra $(\mathrm{KBr})$.

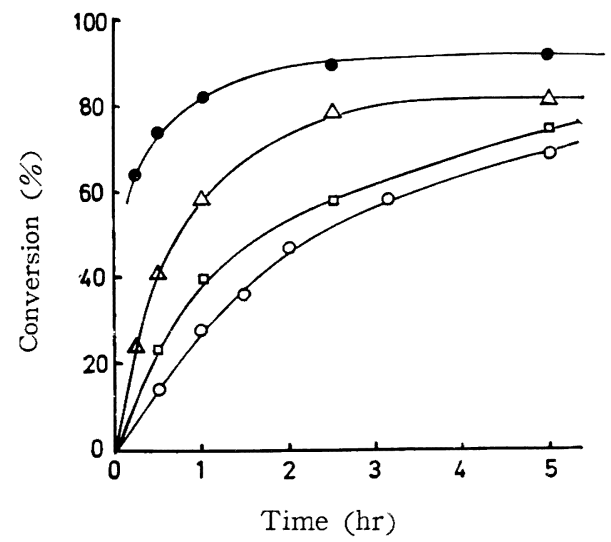

\begin{tabular}{|c|c|c|c|}
\hline & {$[\mathrm{M}](\mathrm{mol} / \mathrm{l})$} & {$[\mathrm{I}] \times 10^{3}(\mathrm{~mol} / \mathrm{l})$} & Temp. $\left(\mathrm{C}^{\circ}\right)$ \\
\hline $\mathrm{I}(\mathbf{0})$ & 0.44 & 3.0 & 80 \\
\hline II $(\Delta)$ & 0.11 & 0.76 & 80 \\
\hline III (口) & 0.11 & 3.0 & 60 \\
\hline IV (O) & 0.11 & 0.76 & 60 \\
\hline
\end{tabular}

Fig. 3. Time-conversion curves for the polymerization of ATVT initiated by AIBN in dioxane.

反応はほとんど誘導期を示さないので, 以後低重合率か ら一点法により初期重合速度を求めた。重合温度 $60^{\circ} \mathrm{C}$ で, モノマー濃度を一定にした場合の重合速度の開始剤
濃度依存性を Fig. 4 に, また, 開始剤濃度を一定にした 場合のモノマー濃度依存性を Fig. 5 と示した。Fig. 4, Fig. 5 より重合速度 $\left(R_{p}\right)$ は開始剂の 0.5 乘に比例し, モノマー濃度の 1 乗 (1.05 乗) に比例することがわか る。また $60^{\circ} \mathrm{C}$ での全重合速度定数 $(k)$ を求めると, その平均値として $2.37 \times 10^{-3}$ が得られ，結局 $60^{\circ} \mathrm{C} て ゙$ の重合速度式として（1）式が得られた。

$$
\begin{array}{r}
R_{p}=2.37 \times 10^{-3}[\mathrm{AIBN}]^{0.5}[\mathrm{ATVT}]^{1.0} \\
(\mathrm{~mol} / l \cdot \mathrm{sec})
\end{array}
$$

(1)式は一般のビニルモノマーの均一重合における速

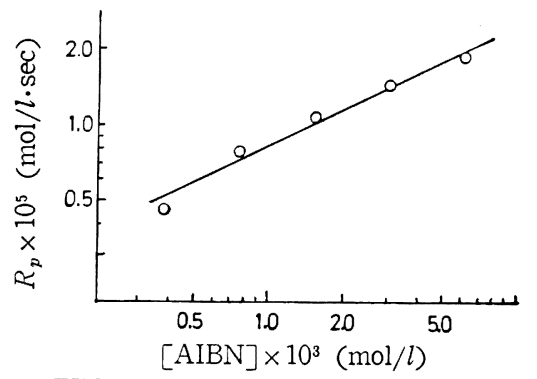

$[\mathrm{ATVT}]=0.11 \mathrm{~mol} / l, 60^{\circ} \mathrm{C}$

Fig. 4. Relation between [AIBN] and $R_{p}$.

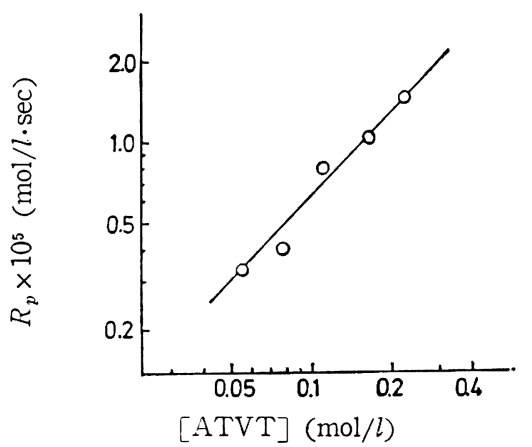

$[\mathrm{AIBN}]=0.76 \times 10^{-3} \mathrm{~mol} / l, 60^{\circ} \mathrm{C}$

Fig. 5. Relation between [ATVT] and $R_{p}$.

Table 2. Polymerization of ATVT at various temperatures.

$[\mathrm{AIBN}]=0.76 \times 10^{-3} \mathrm{~mol} / l, \quad[\mathrm{ATVT}]=0.11$ $\mathrm{mol} / l$ in dioxane

\begin{tabular}{c|c|c}
\hline $\begin{array}{c}\text { Temp. } \\
\left({ }^{\circ} \mathrm{C}\right)\end{array}$ & $\begin{array}{c}R_{p} \times 10^{5} \\
(\mathrm{~mol} / l \mathrm{sec})\end{array}$ & $k^{*} \times 10^{3}$ \\
\hline 50 & 0.22 & 0.72 \\
60 & 0.80 & 2.62 \\
70 & 1.38 & 4.54 \\
75 & 1.90 & 6.25 \\
80 & 2.87 & 9.45 \\
\hline
\end{tabular}

$* k=R_{p} /[\mathrm{ATVT}]^{1.0}[\mathrm{AIBN}]^{0.5}$ 


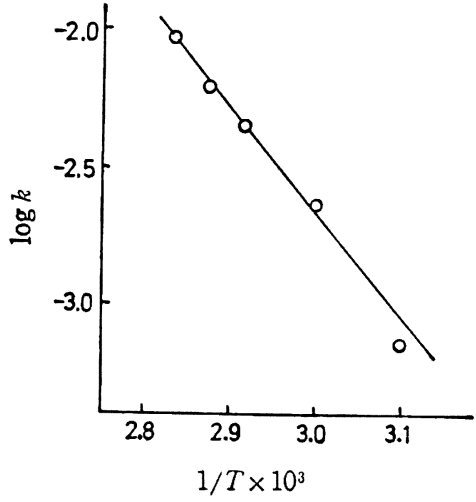

$[\mathrm{ATVT}]=0.11 \mathrm{~mol} / \mathrm{l}$, $[\mathrm{AIBN}]=0.76 \times 10^{-3} \mathrm{~mol} / l$

Fig. 6. Relation between the polymerization temperature and $k$.

度式に一致している。

次に, 重合温度を变えた場合の $R_{p}$ と $k$ とを Table 2 に示す。アルレニウスプロットを示す Fig. 6 より,見か けの活性化ェネルギーとして $16.6 \mathrm{kcal} / \mathrm{mol}$ が得られ た。この値は一般のビニルモノマーのラジカル溶夜重合 の值に比ぺて小さく思われるが，M.M. Koton ${ }^{8)}$ は過酸 化ベンゾイルを用いた 2-ビニルフランのラジカル 重合 において、見かけの活性化ェネルギーとして $17 \mathrm{kcal} / \mathrm{mol}$ を得ている。

なお，アルレニウス式 $k=A \exp (-E / R T)$ より頻度 画子 $A=1.77 \times 10^{8}$ が求められ， $k$ は（2）式で表わさ れる。

$k=1.77 \times 10^{8} \mathrm{exp}(-16600 / R T)$

たとえば, AIBN によるメタクリル酸メチルの重合の kは（3）式で表わされている9。

$k=3.7 \times 10^{9} \exp (-19900 / R T)$

$60^{\circ} \mathrm{C}$ のはMMA が $3.28 \times 10^{-4}$ で10), ATVT か 2. $37 \times 10^{-3}$ である。ATVT の棈造から，かなり立体障 害があると思われたが，奏除には MMA などの共役モ ノマーと比較して, 重合速度が大きく, 立体障害はほと んど考えられない。また 3.2 で述べるようにQ 值がほ ぼ1で, ATVT は共役モノマーと考学られるが, 重合 速度からビニルトリアジンラジカルはかなり活性である と思われる。

なお, 得られたポリマーの粘度は, DMSO 中 $30^{\circ} \mathrm{C} て ゙$ 重台条件により $\eta_{s p} / C=0.15 \sim 0.30(C=0.2 \mathrm{~g} / \mathrm{d} l)$ で あった。重合度はそれほど高くはないようであるが，そ の原因として，一般のビニル重合に比べて，モノマー濃 度が低く, 溶媒への連鎖移動による重合度の低下，ある いはモノマーへの連鎖移動のためと考えられる。いずれ にしても，移動したラジカルは活性を失うことなく，再
びATVTを重合すると思われる。

\section{2 共重合}

$60^{\circ} \mathrm{C}, \mathrm{AIBN}$ 開始剤で ATVT $\left(\mathrm{M}_{2}\right)$ と $\mathrm{MA}, \mathrm{St}$, $\mathrm{AN}$ あるいはV VAc $\left(\mathrm{M}_{1}\right)$ との共重合をジオキサン中で行 った。 $\left[\mathrm{M}_{1}\right]+\left[\mathrm{M}_{2}\right]=0.22 \mathrm{~mol} / l,[\mathrm{AIBN}]=1.5 \times 10^{-3}$ $\mathrm{mol} / l$ とし, 得られた結果を Table 3 に示す。仕込又 モノマーと生成ボリマーの組成の関係を Fig. 7 に示す。 滴定によって共重合体の組成を決定する場合，共重合体 中の ATVT の割合が增すと滴定中に共重合体が析出す るのでいくぶん誤差が含まれる。VAc との共重合体は ホモポリマーの滴定值を使って補正した。MA との共重 合体では元素分析佪と滴定值がよく一致している。

モノマー反応性比 $r_{1}, r_{2}$ を Fineman-Ross 法によっ て求め Table 4 に示す。また得られた $r_{1}, r_{2}$ を使って 求めたモノマーーポリマー組成曲線を Fig. 7 に実線で 示した。ビニルトリアジンラジカルに対する異種モノマ 一とATVT との反応速度の比を示す $1 / r_{2}$ は $\mathrm{AN} \gg \mathrm{St}$ $>\mathrm{MA} \gg \mathrm{VAc}$ である。この順序は, メチルラジカルに対 寸るモノマーの反応性の順序が AN >St であり，ポリス. チリルラジカルに対する反応性の順序が AN $>\mathrm{MA} \geq \mathrm{St}$. >VAc である" こととほぼ同じ傾向を示している。

MA と St との共重合における $r_{1}, r_{2}$ の値からATVT のQ，e 値を計算し，Table 4 に示した。VAcあるいは $\mathrm{AN}$ との $r_{1}, r_{2}$ は誤差が大きいと思われるので $Q, e$ 値 は省略する。St との共重合から求めた $e$ 值が MA との 共重合から求めた $e$ 值よりプラスの側に寄っているが, ビニルピリシンについても同様な傾向が見られる ${ }^{12)} 。$ た St と MAより求めた $Q, e$ 值を平均すると $Q=0.88$, $e=-0.12$ となり, AN のように電子受容性モノマーと かなり共重合性がよいことなどから, ATVT のQ, $e$ 値として妥当な値と思われる。

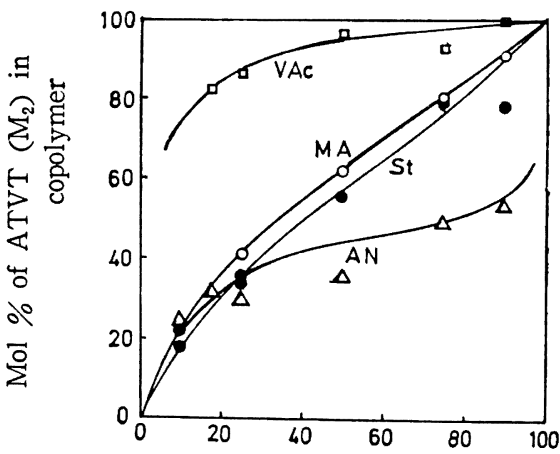

Mol \% of ATVT $\left(\mathrm{M}_{2}\right)$ in monomer

$\triangle$ : ATVT with AN, $\square$ : ATVT with VAc

O: ATVT with MA, - ATVT with St

Fig. 7. Monomer-copolymer composition curves. for ATVT with MA, with St, with AN and with VAc. 
Table 3. Copolymerization of ATVT $\left(\mathrm{M}_{2}\right)$.

$\left(\left[\mathrm{M}_{1}\right]+\left[\mathrm{M}_{2}\right]=0.22 \mathrm{~mol} / l,[\mathrm{I}]=1.5 \times 10^{-3} \mathrm{~mol} / l\right.$, at $60^{\circ} \mathrm{C}$ in dioxane)

\begin{tabular}{|c|c|c|c|c|c|}
\hline \multirow[b]{2}{*}{$\begin{array}{c}\left(\mathrm{M}_{2}\right) \\
\text { in monomer } \\
(\mathrm{mol} \mathrm{\% )})\end{array}$} & \multirow[b]{2}{*}{$\begin{array}{l}\text { Time } \\
(\mathrm{min})\end{array}$} & \multirow[b]{2}{*}{$\begin{array}{l}\text { Conversion } \\
\text { (wt \%) }\end{array}$} & \multicolumn{2}{|c|}{$\left(\mathrm{m}_{2}\right)$ in polymer $(\mathrm{mol} \%)$} & \multirow[b]{2}{*}{$\begin{array}{c}R_{p}{ }^{*} \times 10^{4} \\
(\mathrm{~mol} / / \cdot \mathrm{sec})\end{array}$} \\
\hline & & & $\begin{array}{l}\text { From } \\
\begin{array}{l}\mathrm{C}, \mathrm{N} \text { elemental } \\
\text { analylysis }\end{array}\end{array}$ & $\begin{array}{l}\text { From } \\
\qquad \begin{array}{l}\text { titration } \\
\text { method }\end{array}\end{array}$ & \\
\hline 100 & 30 & 26.8 & & & 3.27 \\
\hline \multicolumn{6}{|c|}{ comonomer $\left[\mathrm{M}_{1}\right]=\mathrm{MA}$} \\
\hline $\begin{array}{l}90 \\
75 \\
50 \\
25 \\
10 \\
\end{array}$ & $\begin{array}{l}30 \\
30 \\
30 \\
30 \\
30 \\
\end{array}$ & $\begin{array}{r}25.3 \\
23.6 \\
15.6 \\
8.3 \\
2.6 \\
\end{array}$ & $\begin{array}{r}91.8 \\
81.9 \\
63.2 \\
43.2 \\
2.6 \\
\end{array}$ & $\begin{array}{l}79.5 \\
62.9 \\
41.5\end{array}$ & $\begin{array}{l}3.03 \\
2.71 \\
1.62 \\
0.77 \\
0.24 \\
\end{array}$ \\
\hline \multicolumn{6}{|l|}{$\left[\mathrm{M}_{1}\right]=\mathrm{St}$} \\
\hline $\begin{array}{l}90 \\
75 \\
50 \\
25 \\
10 \\
25^{* *} \\
10^{* *}\end{array}$ & $\begin{array}{r}60 \\
120 \\
120 \\
120 \\
120 \\
120 \\
120\end{array}$ & $\begin{array}{r}9.0 \\
10.9 \\
7.0 \\
2.1 \\
2.0 \\
4.0 \\
1.8\end{array}$ & 34.4 & $\begin{array}{l}78.7 \\
79.4 \\
56.3 \\
35.3 \\
18.1 \\
34.0 \\
21.8\end{array}$ & $\begin{array}{l}0.55 \\
0.31 \\
0.20 \\
0.06 \\
0.06\end{array}$ \\
\hline \multicolumn{6}{|c|}{$\left[\mathrm{M}_{1}\right]=\mathrm{AN}$} \\
\hline $\begin{array}{l}90 \\
75 \\
50 \\
25 \\
17.5 \\
10\end{array}$ & $\begin{array}{r}30 \\
60 \\
120 \\
120 \\
120 \\
120\end{array}$ & $\begin{array}{r}18.2 \\
21.0 \\
19.7 \\
11.2 \\
10.2 \\
2.8\end{array}$ & 61.9 & $\begin{array}{l}54.3 \\
49.8 \\
35.7 \\
29.9 \\
32.4 \\
24.5\end{array}$ & $\begin{array}{l}3.13 \\
1.69 \\
0.65 \\
0.29 \\
0.25 \\
0.07\end{array}$ \\
\hline \multicolumn{6}{|c|}{$\left[\mathrm{M}_{1}\right]=\mathrm{VAc}$} \\
\hline $\begin{array}{l}90 \\
75 \\
50 \\
25 \\
17.5\end{array}$ & $\begin{array}{r}30 \\
30 \\
60 \\
60 \\
120\end{array}$ & $\begin{array}{r}13.0 \\
14.7 \\
19.5 \\
7.5 \\
12.8\end{array}$ & & $\begin{array}{l}100^{* * *} \\
92.9^{* * *} \\
96.5^{* * *} \\
86.8 \\
82.5\end{array}$ & $\begin{array}{l}1.50 \\
1.55 \\
0.85 \\
0.27 \\
0.23\end{array}$ \\
\hline
\end{tabular}

${ }^{*} R_{p}=-\left(d\left[\mathrm{M}_{1}\right]+d\left[\mathrm{M}_{2}\right]\right) / d t \quad * *\left[\mathrm{M}_{1}\right]+\left[\mathrm{M}_{2}\right]=0.88 \mathrm{~mol} / l,[\mathrm{I}]=6.0 \times 10^{-3} \mathrm{~mol} / \mathrm{l}$

*** corrected with the observed value of poly-ATVT

$Q$ 值が1に近いこと, および先に述べたU スペクト ルの結果から ATVT のビニル基は sートリアシン環と 共役していることがわかる。

なお，Table 3 に共重合速度を付記した。その結果 共重合速度はいずれもATVT濃度の減少とともに減少 している。特に St の場合重合速度の遅延が著しく, ポ リマー末端のスチルラシシカルが安定であることを示して
いる。

\section{4 単独重合体の粘度}

キ酸および DMSO を溶媒として，ホモポリマーの粘 度測定を行なった結果を Fig. 8 亿示す。粘度は DMSO 中に比べキ酸中で著しく大きな値を示し, 固有粘度はギ 酸中，0.99，DMSO 中，0.27である。この原因はアミ ノトリアシンン環の弱塩基性のため, ポリマーがギ酸中で 
Table 4. Copolymerization parameters of ATVT $\left(\mathrm{M}_{2}\right)$.

\begin{tabular}{l|l|c|c|c}
\hline \hline \multicolumn{1}{c|}{$\mathrm{M}_{1}\left(Q_{1}, e_{1}\right)$} & $r_{1}$ & $r_{2}$ & $Q_{2}$ & $e_{2}$ \\
\hline $\mathrm{MA}(0.42,0.60)$ & 0.33 & 1.22 & 0.72 & -0.36 \\
$\mathrm{St}(1.00,-0.8)$ & 0.45 & 0.93 & 1.05 & +0.13 \\
$\mathrm{AN}$ & 0.3 & 0.03 & - & - \\
$\mathrm{VAc}$ & 0.001 & 17 & - & - \\
\hline
\end{tabular}

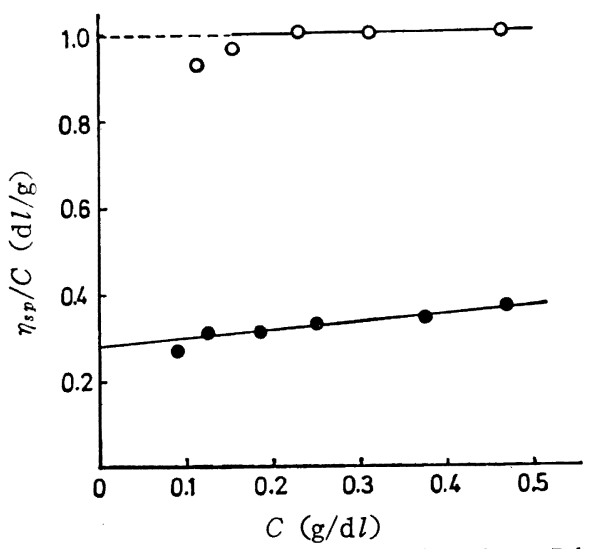

Sample; Fig, 3. No. 1, Reaction time, $5 \mathrm{hr}$.

$O$ : ATVT polymer in formic acid,

- : ATVT polymer in DMSO

Fig. 8. $\quad \eta_{s p} / C$ against $C$ for ATVT polymer in formic acid and DMSO at $30^{\circ} \mathrm{C}$.

電解質的挙動を示すものとおもわれる。

付記：0ートリルビグフニドを提供された大内新興
化学工業株式会社に感謝します。元素分析をしていた だいた本学資源化学研究所池田・山本研究室の斎藤豊 治氏に感謝します。なお，本研究の一部は日化第 17 年会（1964 年 4 月，東京）にて発表した。

\section{文献}

1) C.G. Overberger, S.L. Shapiro: J. Am. Chem. Soc., 76, 1061 (1954)

2) C.G. Overberger, F.W. 'Michellotti: J. Am. Chem. Soc., 80, 988 (1958)

3) A.T. Coscia, R.L. Kugel, J. Pellon: J. Polymet Sci., 55, 303 (1961)

4) a) S.L. Shapiro, V.A. Parrino, L. Freedman: J. Org. Chem., 25, 379 (1960)

b) S.L. Shapiro, V.A. Parrino, L. Freedman: J. Org. Chem., 25, 384 (1960)

5) C.G. Overberger, F.W. Michelotti, P.M. Carabates: J. Am. Chem. Soc., 79, 941 (1957)

6) K. Knappe, D. Peteri: Z. Analyt. Chem., Bd. 194, 417 (1963)

7) W.M. Padgett Il, W.F. Hamner: J. Am. Chem. Soc., 80, 803 (1958)

8) M.M. Koton: J. Polymer Sci., 30, 331 (1958)

9) M. Imoto, T. Otsu, K. Tsuda: J. Polymer Sci., A2, 1407 (1964)

10）山田正盛, 高瀬 晸：高化, 22,626 (1965)

11）バグダサリアン“ラジカル重合の理論”：井本 稔, 二見 成訳, 193 (1964) 朝倉書店

12) T. Tamikado: J. Polymer Sci., 43, 489 (1960)

\title{
Polymerization of 2-amino-4-o-toluidino-6-vinyl-s-triazine
}

\author{
by Yasuo Yuki*, Toshio Kakurai* and Tatsuya Noguchi*
}

A new monomer, 2-amino-4-o-toluidino-6-vinyl-s-triazine (ATVT), was synthesized from the reaction of o-tolylbiguanide with acrylyl chloride.

The homopolymerization of this monomer was carried out at $50 \sim 80^{\circ} \mathrm{C}$ in dioxane with azobisisobutyronitrile (AIBN) as an initiator and the rate of polymerization $\left(R_{p}\right)$ at $60^{\circ} \mathrm{C}$ was represented by following equation.

$$
R_{p}=2.37 \times 10^{-3}[\mathrm{AIBN}]^{0.5}[\mathrm{M}]^{1.0}
$$

Where $[\mathrm{M}]$ is monomer concentration.

The over-all activation energy was obtained to be $16.6 \mathrm{kcal} / \mathrm{mol}$.

The copolymerizations of this monomer $\left(\mathrm{M}_{2}\right)$ with styrene (St), methylacrylate (MA), acrylonitrile (AN) or vinyl acetate (VAc) were also carried out at $60^{\circ} \mathrm{C}$ in dioxane. The monomer reactivity ratios (MRR) were determined as follows:

$$
\begin{array}{rll}
\text { for St-ATVT, } & r_{1}=0.45, & r_{2}=0.93, \\
\text { MA-ATVT, } & r_{1}=0.33, & r_{2}=1.22,
\end{array}
$$

\footnotetext{
* Tokyo Institute of Technology (Ookayama, Meguro-ku, Tokyo)
} 
AN-ATVT, $\quad r_{1}=0.3, \quad r_{2}=0.03$,

VAc-ATVT $, \quad r_{1}=0.001, \quad r_{2}=17$

The $Q$ and $e$ values for ATVT were calculated as 1.05 and $0.13,0.72$ and -0.36 respectively from the MRR values for the copolymerizations with St and with MA. 